OPEN ACCESS

Edited by:

Mark Mapstone,

University of California, Irvine,

United States

Reviewed by:

Martin gorges,

Klinik Für Neurologie, Universität Ulm,

Germany

Giorgia Querin,

Università Degli Studi Di Padova, Italy

*Correspondence:

Foteini Christid

christidi.f.a@gmail.com

Specialty section:

This article was submitted to

Neurodegeneration,

a section of the journal

Frontiers in Neurology

Received: 09 May 2018

Accepted: 13 June 2018

Published: 03 July 2018

Citation:

Christidi F, Karavasilis E, Velonakis G, Ferentinos $P$, Rentzos M, Kelekis $N$, Evdokimidis I and Bede P (2018) The

Clinical and Radiological Spectrum of

Hippocampal Pathology in

Amyotrophic Lateral Sclerosis.

Front. Neurol. 9:523.

doi: 10.3389/fneur.2018.00523

\section{The Clinical and Radiological Spectrum of Hippocampal Pathology in Amyotrophic Lateral Sclerosis}

\author{
Foteini Christidi ${ }^{1 *}$, Efstratios Karavasilis ${ }^{2}$, Georgios Velonakis ${ }^{2}$, Panagiotis Ferentinos ${ }^{3}$, \\ Michail Rentzos ${ }^{1}$, Nikolaos Kelekis ${ }^{2}$, Ioannis Evdokimidis ${ }^{1}$ and Peter Bede ${ }^{4}$ \\ ${ }^{1}$ First Department of Neurology, Aeginition Hospital, National and Kapodistrian University of Athens, Athens, Greece, \\ ${ }^{2}$ Second Department of Radiology, General University Hospital "Attikon," National and Kapodistrian University of Athens, \\ Athens, Greece, ${ }^{3}$ Second Department of Psychiatry, General University Hospital "Attikon," National and Kapodistrian \\ University of Athens, Athens, Greece, ${ }^{4}$ Computational Neuroimaging Group, Academic Unit of Neurology, Trinity College \\ Dublin, Dublin, Ireland
}

Hippocampal pathology in Amyotrophic Lateral Sclerosis (ALS) remains surprisingly under recognized despite compelling evidence from neuropsychology, neuroimaging and neuropathology studies. Hippocampal dysfunction contributes significantly to the clinical heterogeneity of ALS and requires structure-specific cognitive and neuroimaging tools for accurate in vivo evaluation. Recent imaging studies have generated unprecedented insights into the presymptomatic and longitudinal processes affecting this structure and have contributed to the characterisation of both focal and network-level changes. Emerging neuropsychology data suggest that memory deficits in ALS may be independent from executive dysfunction. In the era of precision medicine, where the development of individualized care strategies and patient stratification for clinical trials are key priorities, the comprehensive review of hippocampal dysfunction in ALS is particularly timely.

Keywords: hippocampus, amyotrophic lateral sclerosis, neuropathology, neuroimaging, cognition

\section{INTRODUCTION}

Amyotrophic lateral sclerosis (ALS) is relentlessly progressive neurodegenerative condition with considerable clinical heterogeneity (1). One of the key clinical dimensions of disease heterogeneity in ALS is the varying severity and profile of cognitive impairment. The quality of life implications of cognitive impairment in ALS and its impact on caregiver burden (2), compliance with assistive devices (3) and survival (4) are now universally recognized. The discovery of hexanucleotide expansions in C9orf72 in 2011 (5) has given fresh momentum to neuropsychology research in ALS by confirming shared etiological factors between frontotemporal dementia (FTD) and ALS. The momentous conceptual advances in the neuropsychology of ALS have taken place in a remarkably short period of time, from sporadic observations, through the development of diagnostic criteria (6), to robust family aggregation (7) and genetic studies, to the development of disease-specific screening instruments $(8,9)$. The current consensus criteria (6) distinguish ALS with cognitive impairment; ALS with behavioral impairment; ALS with cognitive and behavioral impairment; ALS-FTD; ALS-dementia (non-FTD, i.e., Alzheimer dementia (AD), vascular dementia, 
mixed dementia). One of the most exciting aspects of ALS neuropsychology studies is their localization potential to specific anatomical circuits and that their observations are widely corroborated by neuropathology (10-12) and neuroimaging studies (13). Memory deficits in ALS have traditionally been regarded as atypical and considered suggestive of coexisting AD-type pathology. The recognition that memory deficits are part of the spectrum of ALS-associated cognitive impairment is relatively recent.

\section{MEMORY IMPAIRMENT IN ALS}

Early neuropsychology studies of ALS have predominantly examined frontal lobe-mediated neuropsychological domains, and highlighted executive dysfunction, impaired phonemic fluency, poor set shifting, reduced cognitive flexibility, impaired response inhibition, planning deficits, problemsolving difficulties, selective attention, and impaired social cognition (14). More recently, the spectrum of memory impairment has been specifically evaluated, including encoding and retrieval functions (primary memory system) $(15,16)$ and storage/consolidation domains (secondary memory system) (17). Furthermore, population-based studies identified cognitive phenotypes without executive impairment $(18,19)$. The description of episodic memory deficits without coexisting executive dysfunction in ALS drew attention to temporal lobe network dysfunction which has been elegantly corroborated by a series of neuropathology and neuroimaging studies (20).

\section{ANATOMICAL OVERVIEW}

The hippocampus (Figure 1A) is a bilaminar structure and consists of the cornu ammonis (CA) and the dentate gyrus (DG). Based on its cytoarchitecture and projections, the CA is further divided into four histological subfields, named CA1-CA4 by Lorente de No in his seminal paper (21). The dentate gyrus is a narrow, dorsally concave structure which envelops CA4. The cornu ammonis, the dentate gyrus, and the subiculum together form the "hippocampal formation" (Figure 1B). The subiculum is divided into the following segments: the prosubiculum, the subiculum proper, the presubiculum, and the parasubiculum.

Each segment of the hippocampal formation receives afferentation from its neighboring regions but these connections are not all bidirectional (22). For example, the "trisynaptic circuit" (23) is a unidirectional network, which arises from layer

\footnotetext{
Abbreviations: ALS, amyotrophic lateral sclerosis; ALSFRS-r, revised ALS functional rating scale revised; ALSnci, ALS with no cognitive impairment; aMCI, amnestic mild cognitive impairment; C9orf72 HRT, chromosome 9 open reading frame 72 hexanucleotide repeats; CA, cornu ammonis; DG, dentate gyrus; DTI, diffusion tensor imaging; DWI, diffusion weighted imaging; ECAS, Edinburgh cognitive and behavioral ALS screen; FTD, frontotemporal dementia; GM, gray matter; HARDI, high angular resolution diffusion imaging; $\mathrm{HC}$, healthy control; MND, motor neuron disease; NeuroC, neurological controls; NODDI, neurite orientation dispersion and density imaging; PP, perforant pathway; PtwoCI, patients without cognitive impairment; PtwCI, patients with cognitive impairment; PtwoD, patients without dementia; PtwD, patients with dementia; TBSS, tract-based spatial statistics; VBM, voxel-based morphometry; WM, white matter; MRS, magnetic resonance spectroscopy.
}

II of the entorhinal cortex, its axons perforate the subiculum, and form the "perforant pathway" (PP). Duvernoy (24) coined the term "polysynaptic pathway" for the intrinsic hippocampal circuitry, which refers to a circuit of at least four synapses that connect the entorhinal cortex, the dentate gyrus, the CA subfields, and the subiculum. A direct intrahippocampal pathway has also been identified, which originates from layer III of the entorhinal cortex and projects directly to the CA1 but not through the PP (25). The perforant pathway (Figure 1C) arises from layer II-III neurons of the lateral and medial entorhinal cortex (26), which is also the origin of the polysynaptic pathway (27). The PP perforates the subiculum to reach the dentate gyrus and the hippocampus proper, but minor projections also originate from the presubiculum and parasubiculum (28). The majority of the PP fibers reach the stratum moleculare of the dentate gyrus through the vestigial hippocampal sulcus (24). The PP contributes to the "Papez circuit" $(26,29,30)$ which is relayed through the following structures; entorhinal cortex $\rightarrow$ dentate gyrus $\rightarrow$ hippocampus $\rightarrow$ hypothalamus $\rightarrow$ thalamus $\rightarrow$ cingulate cortex $\rightarrow$ presubiculum $\rightarrow$ entorhinal cortex. In addition to the intrinsic hippocampal circuitry, there are numerous extrinsic hippocampal projections to subcortical and cortical regions (31). The main input to the hippocampus enters via the entorhinal area (31).

\section{INSIGHTS FROM NEUROPATHOLOGY}

Neuropathological changes have been consistently reported in the hippocampus in ALS (Table 1). Early reports highlighted ubiquitin-positive intraneuronal inclusions (32-35) in medial temporal structures, neuronal loss in the medial cortex of the temporal tip $(36,69)$ and focal depletion of pyramidal neurons in the pes hippocampi in both patients with and without dementia $(33,36,69)$. A specific focus of interest in histopathological studies is the PP zone, which has been comprehensively studied in most neurodegenerative conditions, especially in AD. While $\mathrm{AD}$ is characterized by the extraneuronal deposits of the amyloid $\beta$-protein $(\mathrm{A} \beta)$ and the intraneuronal tauopathy (70), ALS is primarily associated with TAR DNA-binding protein 43 (TDP43) deposits (71). ALS patients with and without dementia (37, 38) show neuropathological changes in the dentate gyrus and the outer lamina of the molecular layer where the PP terminals are distributed $(26,30,72)$. In ALS, the molecular layer of the dentate gyrus is primarily affected, a pattern which is distinctly different from $\mathrm{AD}$. The inner molecular layer, which is innervated by the CA4 (73), is the least affected layer in ALS (38). The intermediate layer, which receives projections from layer II of the medial entorhinal cortex, is affected (38), but the outer layer, is the most affected region in ALS (38). Despite considerable mesial temporal lobe involvement in both ALS and $\mathrm{AD}$, the distribution of disease-specific inclusions is strikingly different. Neurofibrillary tangles in $\mathrm{AD}$ are mostly found in the entorhinal cortex and are positive for tau, whereas the main proteinopathy of ALS is TDP-43 and mostly affects the transentorhinal cortex (38).

It is now widely recognized that phosphorylated TDP-43 (pTDP-43) aggregates are the hallmark pathology of sporadic 


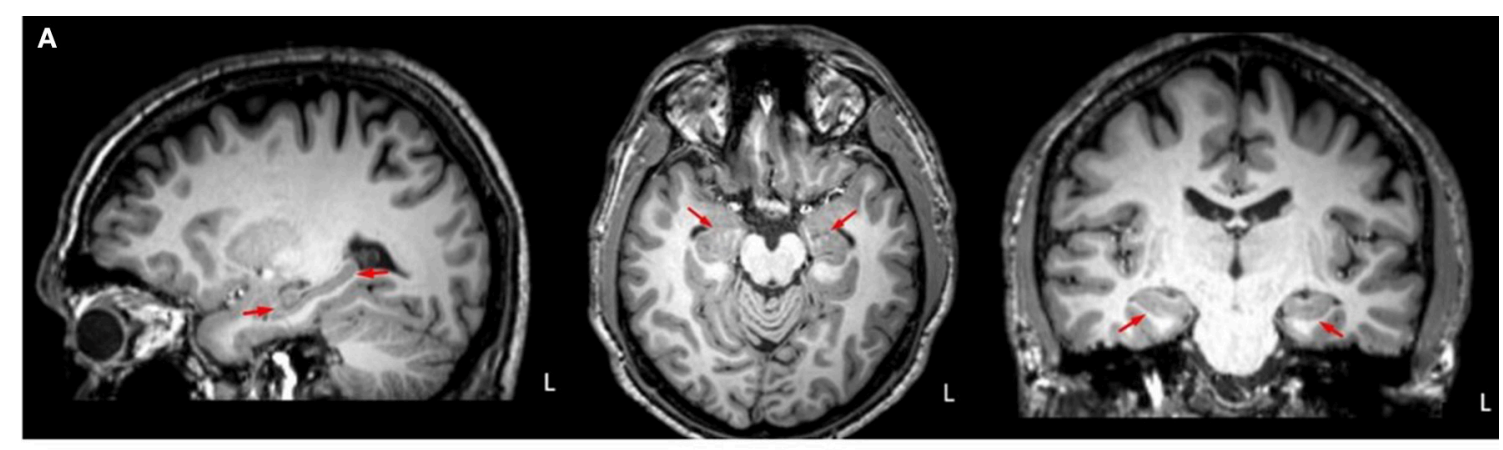

B

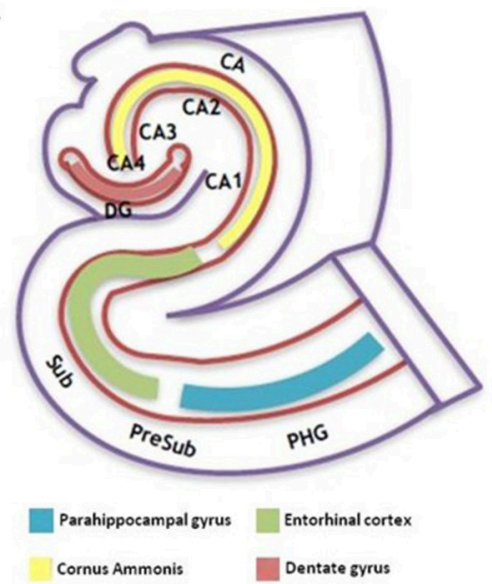

C

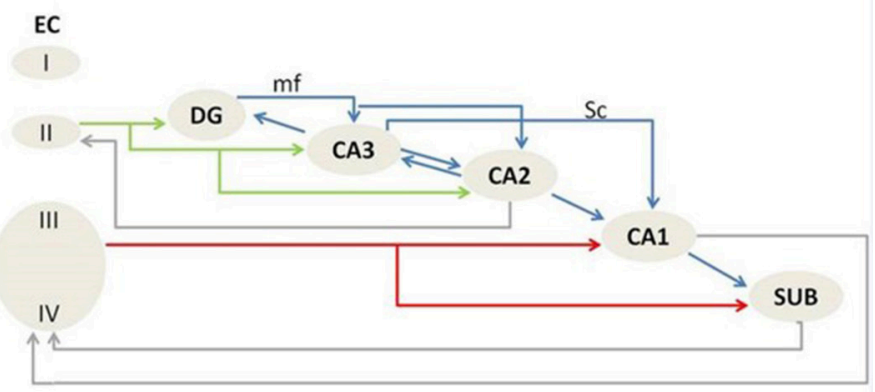

FIGURE 1 | Anatomical depiction of hippocampus on sagittal, axial and coronal plane of high resolution T1 image from a healthy control subject (A) and schematic representation of (B) the anatomy of the hippocampus-entorhinal cortex-parahippocampal gyrus system and (C) the intrahippocampal connections. L, left hemisphere; PHG, parahippocampal gyrus; PreSub, Presubiculum; Sub, Subiculum; CA, Cornu Ammonis; CA1-CA4, Cornu Ammonis subfields; DG, Dentate gyrus; EC, Entorhinal cortex; I-IV, Layer I-IV; mf, mossy fibers; Sc, Schaffer collaterals.

$\operatorname{ALS}(39,74,75)$. Based on post mortem observations, a sequential staging system of pTDP-43 pathology has been proposed, using stage-defining involvement of specific cortical and subcortical regions (12). According to this four-stage model of disease propagation, the PP is predominantly affected in stage IV. A three-stage model has also been suggested for PP degeneration (38) where stage I is the "inclusion stage" defined by TDP43-positive cytoplasmatic inclusions appearing in the granular cells of the dentate gyrus, stage II is the "early perforant stage" where gliosis and neuronal loss of the transentorhinal cortex are observed, and stage III is the "advanced perforant stage" defined by the degeneration of the molecular layer of the dentate gyrus and neuronal loss in the transentorhinal cortex (38). The chronological stages of hippocampal pathology are closely linked to its structural anatomy, confirming that disease propagation occurs along connectivity patterns (76). The TDP-43 stages of ALS are in line with the notion that gray matter (GM) regions become sequentially involved via the WM pathways that connect them (77-79).

\section{THE CONTRIBUTION OF NEUROIMAGING}

Neuroimaging studies have already contributed meaningful structural, metabolic and functional insights in ALS (80,
81) and recent technological advances in imaging techniques offer unprecedented opportunities to characterize hippocampal changes in vivo. Following sporadic reports of hippocampal degeneration (82-85) in whole-brain exploratory studies, recent studies have specifically focused on the evaluation of this structure (43) (Table 1). Emerging imaging methods not only highlight hippocampal volume reductions, but have the potential to characterize specific sub-regions (78), shape changes (42), density alterations (20), progressive longitudinal changes (43), altered connectivity profiles, and functional changes $(40,46,47)$.

\section{Structural Neuroimaging}

Computational neuroimaging techniques have consistently captured hippocampal GM changes which was initially thought to be more significant in ALS patients carrying the C9orf72 hexanucleotide repeats (40), but later studies showed similarly extensive hippocampal degeneration in C9orf72 negative ALSFTD patients (78). Interestingly, unilateral hippocampal changes were not only captured in patients with cognitive impairment (42), but also in cognitively intact cohorts (41). Shape and density analyses of the hippocampus in ALS highlighted phenotype-specific patterns of hippocampal degeneration (42). A longitudinal study of hippocampus, which included a small ( $\sim 6 \%)$ number of C9orf72 positive patients, identified baseline 
TABLE 1 | Research studies with hippocampal-related neuropathological, neuroimaging, or neuropsychological findings in ALS included in the present review.

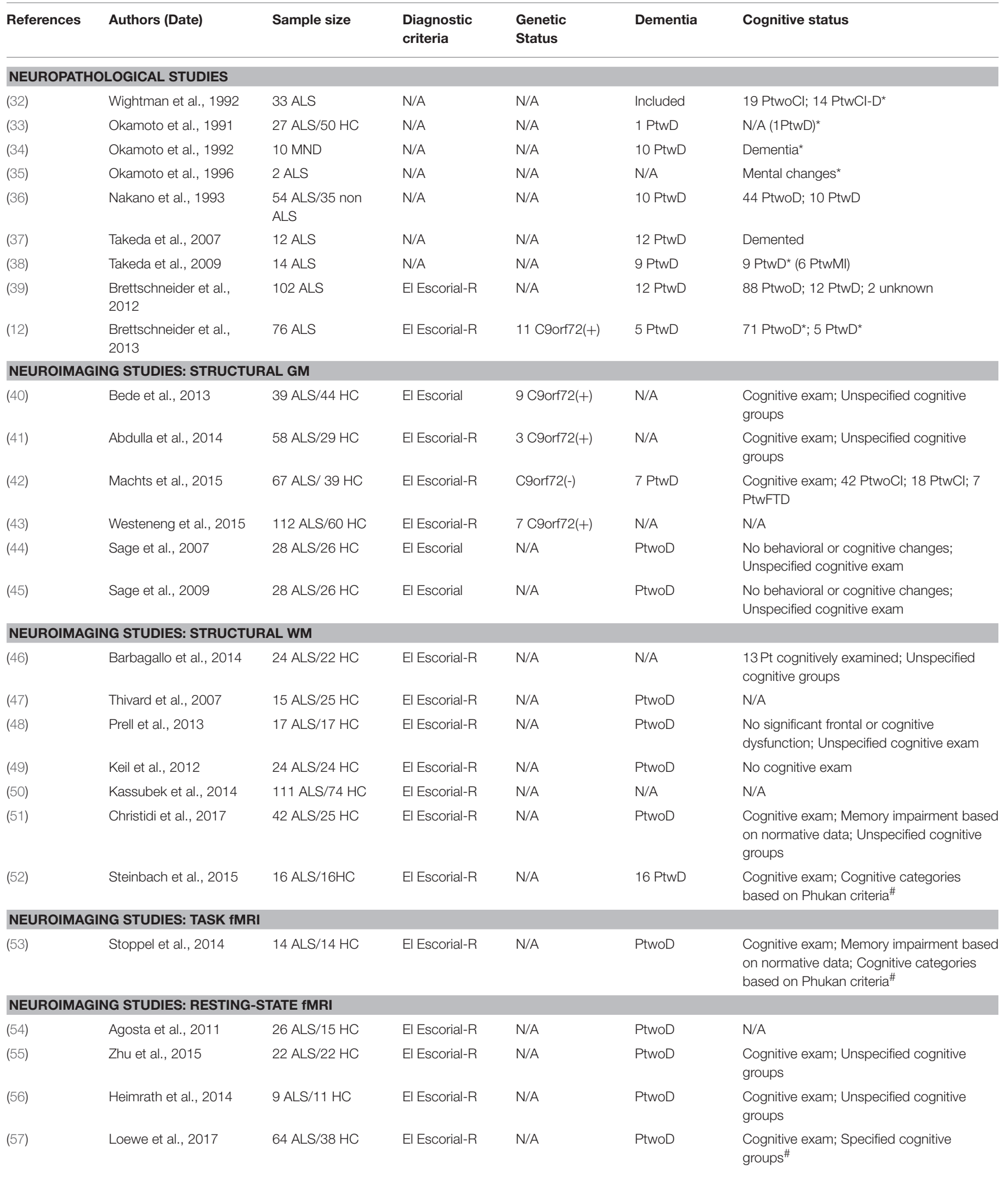


TABLE 1 | Continued

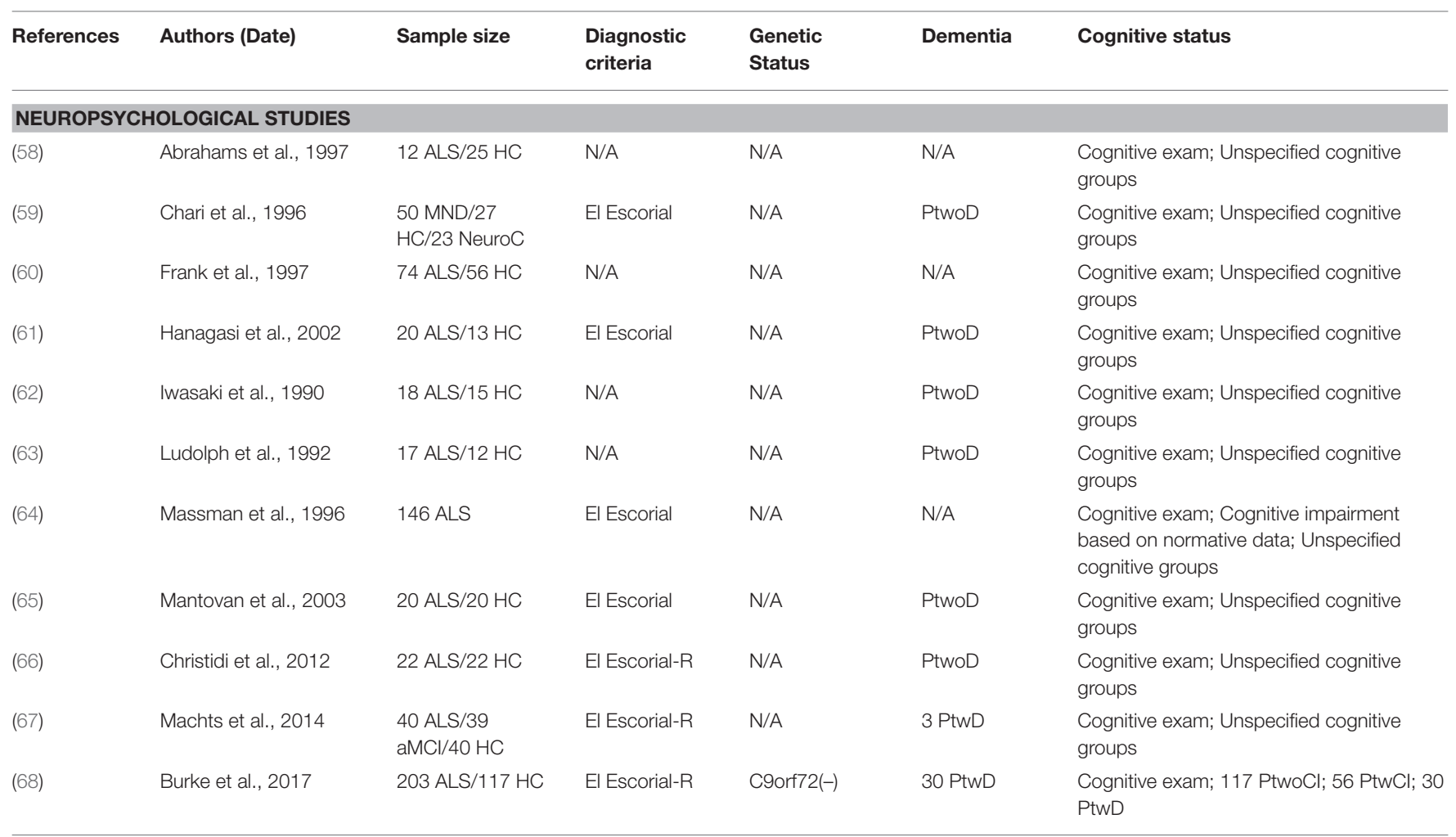

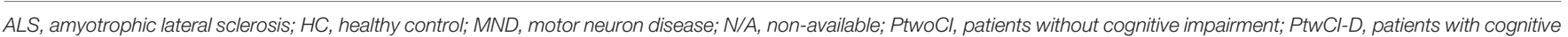

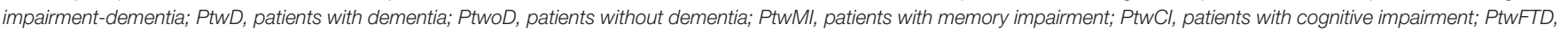

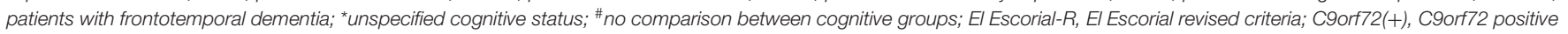
status; GM, gray matter; WM, white matter.

changes in the left presubiculum, and progressive CA2/3, CA4 and the left presubiculum involvement at follow-up (43).

While diffusion-weighted imaging (DWI) is primarily used to study white matter (WM) structures, there is increasing evidence that it may provide useful information on aspects of GM integrity (86). Evaluation of diffusion tensor imaging (DTI) metrics have consistently shown low fractional anisotropy (44, 49) and increased mean diffusivity in both hippocampal (44-47) and parahippocampal regions (48).

DTI has been initially used to characterize medial temporal lobe WM regions and later to assess limbic circuit integrity (i.e., fornix; uncinate fasciculus) (87-89). One of the most unique applications of hippocampal DTI in ALS however is the ability to reconstruct and evaluate of the PP. (50, 51). Based on in vivo assessments, these studies have not only confirmed previous neuropathological observations but also revealed structure-specific clinical correlations (51). The use of DWI-based PP imaging (90) has contributed to our understanding of impaired memory processing in a range of conditions from mild cognitive impairment, through $\mathrm{AD}$, to traumatic brain injury (91-94). PP imaging is therefore a relatively well-established approach which has only recently been applied to ALS. A longitudinal tractography study of ALS (52) found increased connectivity between the visual cortex and medial temporal lobe regions which increased further at 3-month follow-up. Increased connectivity over time in ALS is not an isolated finding (95) and is often interpreted as a compensatory mechanism.

\section{Functional Neuroimaging}

There are relatively few paradigm-based functional magnetic resonance imaging (fMRI) studies specifically evaluating hippocampal function, but a longitudinal fMRI study identified increased novelty-evoked hippocampal activity over time (53). Resting-state studies have consistently captured increased connectivity between the left sensorimotor cortex and contralateral cortical regions including the parahippocampal gyrus (54). Additionally, increased low-frequency amplitudes have been observed in the right parahippocampal cortex (55). Increased functional connectivity was also identified between parahippocampal components of the default-mode network (56). In a relatively large sample of ALS patients with only minor cognitive changes, (57) decreased functional connectivity was identified between temporal lobe structures, including hippocampal and parahippocampal regions. This was thought to represent early metabolic disturbances before cell-loss occurs but highlight the fact that increased and decreased connectivity is both reported in fMRI studies of ALS. 


\section{INSIGHTS FROM NEUROPSYCHOLOGY}

Contrary to the consensus around executive dysfunction in ALS (96-99), there are strikingly inconsistent reports about the incidence of memory impairment in ALS (Table 1). Intact memory function, mild dysfunction, executive function mediated memory impairment, and moderate memory deficits have all been reported $(58-65,97)$. The primary substrate of amnestic deficits is still under investigation. Most studies agree that the primary deficit is in encoding-retrieval (65) which is often linked to frontal dysfunction, attention, and other executive-based processes (65-68). However, recognition deficits and memory consolidation difficulties are likely to be just as important (66). Compelling evidence also exist for pure episodic memory dysfunction based on impaired picture recall, word list-learning, pair associations, and story-recall. These observations would suggest that memory impairment in non-demented ALS patients cannot be exclusively attributed to executive dysfunction (100102).

In a combined neuroimaging-neuropsychology study, abnormal immediate and delayed recall scores were identified in $23 \%$ of non-demented ALS patients (102). While the ALS cohort of this study did not exhibit reduced hippocampal volumes in comparison to healthy controls, their memory performance correlated with hippocampal volumes. These findings are echoed by other studies which rely on volumetric analyses and verbal list-learning test and report significant correlations between the hippocampal volumes and verbal memory indices such as total learning, delayed recall, and recognition (41).

While direct clinico-radiological correlations are often regarded as contentious (103), a positive association has been reported between verbal memory indices and hippocampal volumes in several ALS subgroups, including ALSci and ALSFTD (42). DTI studies have consistently revealed correlations between memory performance and memory-associated WM tracts such as the fornix (88), the uncinate fasciculus $(87,88)$, and the hippocampal PP (51). Emerging reports of similar episodic memory performance in ALS and amnestic mild cognitive impairment patients (67) corroborates neuropathological findings of comparable PP changes $(37,38)$.

\section{Testing Recommendations}

Traditionally, the assessment of episodic memory includes tests for immediate and delayed recall, and performance evaluated from a learning, retention and recognition perspective. More recently, distinct memory processes are specifically assessed, such as encoding, consolidation, and retrieval. (104-106) Listlearning tests (e.g., California Verbal Learning Test; Rey Auditory Verbal Learning Test; Hopkins Verbal Learning Test etc.) are particularly useful to assess hippocampus-mediated verbal memory dysfunction in ALS. These tests enable the clinician to evaluate immediate recall, delayed recall, and recognition and can be readily interpreted in terms of encoding, consolidation, and retrieval performance (66). Story-recall tests, such as the Wechsler-Memory Scale, are also sensitive to detect episodic memory impairment and ideally, both list-learning and storyrecall should be performed to comprehensively evaluate episodic memory in ALS. The accurate assessment of visual episodic memory is often confounded by motor disability in in ALS or by coexisting executive dysfunction which may affect the organization and encoding of complex figures (e.g., ReyOsterreith Complex Figure Test). The limitations of short, nonALS, cognitive screening tools such as MMSE; ACE; MoCA are widely recognized in the ALS research community, as these tests have been developed for other neurodegenerative conditions. The administration of ALS specific screening tools (ECAS, ALS-CBS) should be followed by specialist neuropsychological evaluation if memory impairment is identified or reported by the patient or caregiver.

\section{DISCUSSION}

The synthesis of insights from neuropathology, neuroimaging and neuropsychology enables the systematic discussion of structural and functional aspects of hippocampal degeneration in ALS and helps to integrate focal pathology into a network perspective.

While hippocampal pathology used to be primarily evaluated in ALS patients with comorbid dementia $(34,37,38)$, recent studies have increasingly focused on non-demented patient cohorts $(12,32,69,71)$. With the increased recognition of neuropsychological deficits beyond executive dysfunction, imaging studies of ALS have gradually started to evaluate mesial temporal lobe structures and memory domains have now been incorporated in ALS-specific cognitive screening tools (8). The targeted evaluation of memory function and reliance on more sophisticated indices of episodic memory (65-68) not only help to characterize the heterogeneity of cognitive profiles but also confirm that pure episodic memory dysfunction is not uncommon in ALS and can be detected in the absence of FTD.

Despite the momentous advances in characterizing hippocampal degeneration in ALS, considerable shortcomings and inconsistencies can be identified. The commonest problem is sample size limitations followed by the inclusion of poorly characterized patients. The comprehensive neuropsychological assessment of patients is paramount and administering screening tests alone is not sufficient. Reliance on non-ALS specific batteries, such as Addenbrooke's Cognitive Examination, MiniMental State Examination, Montreal Cognitive Assessment, is not sufficient to characterize ALS-associated cognitive change. A common shortcoming of ALS neuropsychology papers is overlooking the confounding effect of medications which affect cognitive performance. Anticholinergics commonly used for sialorrhea, tricyclic antidepressants, opiates, benzodiazepines are all widely used in ALS and have a significant impact on attention, registration, and recall. Other disease-specific confounding factors such as hypoxia, hypercapnia, physical discomfort, fatigue, apathy, low mood, depression also need careful consideration. Despite established consensus criteria (6) different batteries are used in different centers to test memory. There is a paucity of reports where caregivers or family members are interviewed about the sort of memory impairment they may have observed. A few targeted questions if the patient 
gets lost in familiar places, misplaces items, forgets names, or dates etc. may be worth asking from the caregivers. Given the strikingly quick progression rates observed in ALS compared to other neurodegenerative conditions, resource allocation, care planning, assessment of capacity may be important at an early stage of the disease. ALS patients have to make a number of important financial, personal, and end-of-life decisions which may or may not be affected by memory impairment.

The practice of excluding patients with dementia in neuroimaging studies $(44,47,49,55)$ to evaluate clinically homogenous samples may also be counterintuitive. More recent imaging papers include comprehensive cognitive testing (5557) which aids the interpretation of extra-motor changes (107). The lack of cognitive profiling of the healthy controls in many neuroimaging studies also precludes robust statistics as only the patient group is then used for correlative analyses. Often, reference normative neuropsychology data are used for the interpretation of patient's memory performance, data which is independent from the given study and originate from volunteers who have not been scanned as part of the given study. The patients' neuroimaging data on the other hand are contrasted to scans of controls who had no detailed neuropsychological evaluation. This unfortunately is a common study design, which essentially uses a different imaging and neuropsychology control group. Another common shortcoming of ALS neuroimaging studies is the lack of adjustment for education, which may impact on both structural and functional imaging data (80). A binary, comparative study design of patients versus controls and the contrasting of two clinically or genetically defined cohorts is not entirely satisfactory either. The inclusion of mimic cohorts, or a "disease-control" group with an alternative neurodegenerative condition such as MCI, AD, or Parkinson disease would also be desirable. The selection bias of relatively well patients who are able to lie flat in the scanner and able to make the journey to a radiology department is seldom acknowledged. It is conceivable that progressive hippocampal changes occur as the disease progresses, but these patients are no longer able to partake in imaging studies. Clinical trial designs are not only hampered by late recruitment of clinically heterogeneous cohorts, but they overwhelmingly rely on motor, respiratory, nutritional markers (108-110). Patient stratification based on cognitive performance prior to inclusion and monitoring performance during the trial seems essential, especially given the survival implications of cognitive impairment $(3,4,111)$.

Despite initial enthusiasm that hexanucleotide repeats account for most of the ALS-FTD cohort $(112,113)$, it has quickly become apparent that C9orf72 hexanucleotide repeats

\section{REFERENCES}

1. Brooks BR, Miller RG, Swash M, Munsat TL, World Federation of Neurology Research Group on Motor Neuron Diseases. El Escorial revisited: Revised criteria for the diagnosis of amyotrophic lateral sclerosis. Amyotroph Lateral Scler Other Motor Neuron Disord. (2000) 1:293-9. doi: 10.1080/146608200300079536

2. Burke T, Elamin M, Galvin M, Hardiman O, Pender N. Caregiver burden in amyotrophic lateral sclerosis: a cross-sectional investigation of predictors. $J$ Neurol. (2015) 262:1526-32. doi: 10.1007/s00415-015-7746-z only explain a minority of ALS-FTD cases (114). Emerging studies confirm that a subgroup of C9orf72 negative patients may show neuroanatomical alterations similar to the ones observed in patients carrying the hexanucleotide expansion. Furthermore, temporal lobe changes have been captured in asymptomatic hexanucleotide carriers, who also exhibited subcortical gray matter degeneration prior to symptom onset (115).

Existing multimodal studies which combine neuroimaging and neurocognitive measures either support a close association between anatomical changes and memory performance or highlight a relative dissociation between the two methods. This inconsistency is epitomized by reports of absent neuroimaging changes in patients with established memory deficits and the detection of significant hippocampal changes in patients with mild memory impairment $(41,42,102)$. Based on the shortcomings of existing hippocampal studies in ALS, future studies should include large sample sizes, disease-controls, longitudinal designs, paradigm-based fMRI, comprehensive neuropsychological profiling, "disease-controls," anatomical corrections for education, and genetic screening for mutations implicated in ALS, FTD, and AD. Furthermore, reliance on high directional diffusion models such as neurite orientation dispersion and density imaging (NODDI), high angular resolution diffusion imaging (HARDI), or Q-ball imaging may be desirable to characterize early WM alterations in parahippocampal regions. Finally, combined imaging and postmortem studies may provide a validation of the in vivo findings.

In conclusion, hippocampal pathology is a clinically and academically relevant field of ALS research which has gained unprecedented momentum in recent years and is likely to contribute important further insights in the coming years.

\section{AUTHOR CONTRIBUTIONS}

The paper was drafted by FC, EK, and $\mathrm{PB}$ and has been reviewed for intellectual content by GV, PF, MR, NK, and IE.

\section{ACKNOWLEDGMENTS}

We acknowledge the generosity and kindness of our patients for participating in ALS imaging studies worldwide. PB is supported by the Health Research Board (HRBIreland; HRB EIA-2017-019), the Irish Institute of Clinical Neuroscience IICN-Novartis Ireland Research Grant, the Iris O'Brien Foundation, the Perrigo Clinician-Scientist Research Fellowship, and the Research Motor Neuron (RMN-Ireland) Foundation.

3. Olney RK, Murphy J, Forshew D, Garwood E, Miller BL, Langmore S, et al. The effects of executive and behavioral dysfunction on the course of ALS. Neurology (2005) 65:1774-7. doi: 10.1212/01.wnl.0000188759.87 $240.8 \mathrm{~b}$

4. Elamin M, Phukan J, Bede P, Jordan N, Byrne S, Pender N, et al. Executive dysfunction is a negative prognostic indicator in patients with ALS without dementia. Neurology (2011) 76:1263-9. doi: 10.1212/WNL.0b013e318214359f

5. DeJesus-Hernandez M, Mackenzie Ian R, Boeve Bradley F, Boxer Adam L, Baker M, Rutherford Nicola J, et al. Expanded GGGGCC hexanucleotide 
repeat in noncoding region of C9ORF72 causes chromosome 9p-linked FTD and ALS. Neuron. (2011) 72:245-56. doi: 10.1016/j.neuron.2011.09.011

6. Strong MJ, Abrahams S, Goldstein LH, Woolley S, McLaughlin P, Snowden J, et al. Amyotrophic lateral sclerosis - frontotemporal spectrum disorder (ALS-FTSD): Revised diagnostic criteria. Amyotroph Lateral Scler Other Motor Neuron Disord. (2017) 18:153-74. doi: 10.1080/21678421.2016.1267768

7. O’Brien M, Burke T, Heverin M, Vajda A, McLaughlin R, Gibbons J, et al. Clustering of neuropsychiatric disease in first-degree and second-degree relatives of patients with amyotrophic lateral sclerosis. JAMA Neurol. (2017) 74:1425-30. doi: 10.1001/jamaneurol.2017.2699

8. Abrahams S, Newton J, Niven E, Foley J, Bak TH. Screening for cognition and behaviour changes in ALS. Amyotroph Lateral Scler Other Motor Neuron Disord. (2014) 15:9-14. doi: 10.3109/21678421.2013.805784

9. Woolley SC, York MK, Moore DH, Strutt AM, Murphy J, Schulz PE, et al. Detecting frontotemporal dysfunction in ALS: utility of the ALS Cognitive Behavioral Screen (ALS-CBS). Amyotroph Lateral Scler. (2010) 11:303-11. doi: 10.3109/17482961003727954

10. Saberi S, Stauffer JE, Schulte DJ, Ravits J. Neuropathology of amyotrophic lateral sclerosis and its variants. Neurol Clin. (2015) 33:855-76. doi: 10.1016/j.ncl.2015.07.012

11. Fatima M, Tan R, Halliday GM, Kril JJ. Spread of pathology in amyotrophic lateral sclerosis: assessment of phosphorylated TDP43 along axonal pathways. Acta Neuropathol Commun. (2015) 3:47. doi: 10.1186/s40478-015-0226-y

12. Brettschneider J, Del Tredici K, Toledo JB, Robinson JL, Irwin DJ, Grossman $\mathrm{M}$, et al. Stages of pTDP-43 pathology in amyotrophic lateral sclerosis. Annals Neurol. (2013) 74:20-38. doi: 10.1002/ana.23937

13. Turner MR, Verstraete E. What does imaging reveal about the pathology of amyotrophic lateral sclerosis? Curr Neurol Neurosci Rep. (2015) 15:45. doi: 10.1007/s11910-015-0569-6

14. Murphy J, Henry R, Lomen-Hoerth C. Establishing subtypes of the continuum of frontal lobe impairment in amyotrophic lateral sclerosis. Arch Neurol. (2007) 64:330-4. doi: 10.1001/archneur.64.3.330

15. Beeldman E, Raaphorst J, Klein Twennaar M, de Visser M, Schmand BA, de Haan RJ. The cognitive profile of ALS: a systematic review and meta-analysis update. J Neurol Neurosurg Psychiatry (2016) 87:611-9. doi: 10.1136/jnnp-2015-310734

16. Raaphorst J, de Visser M, Linssen WH, de Haan RJ, Schmand B. The cognitive profile of amyotrophic lateral sclerosis: a meta-analysis. Amyotroph Lateral Scler. (2010) 11:27-37. doi: 10.3109/17482960802645008

17. Papanicolaou AC. The Amnesias A Clinical Textbook of Memory Disorders. New York, NY: Oxford University Press (2006).

18. Phukan J, Elamin M, Bede P, Jordan N, Gallagher L, Byrne S, et al. The syndrome of cognitive impairment in amyotrophic lateral sclerosis: a population-based study. J Neurol Neurosurg Psychiatry (2012) 83:102-8. doi: 10.1136/jnnp-2011-300188

19. Montuschi A, Iazzolino B, Calvo A, Moglia C, Lopiano L, Restagno G, et al. Cognitive correlates in amyotrophic lateral sclerosis: a populationbased study in Italy. J Neurol Neurosurg Psychiatry (2015) 86:168-73. doi: 10.1136/jnnp-2013-307223

20. Bede P, Bokde A, Elamin M, Byrne S, McLaughlin RL, Jordan N, et al. Grey matter correlates of clinical variables in amyotrophic lateral sclerosis (ALS): a neuroimaging study of ALS motor phenotype heterogeneity and cortical focality. J Neurol Neurosurg Psychiatry (2013) 84:766-73. doi: 10.1136/jnnp-2012-302674

21. Lorente De Nó R. Studies on the structure of the cerebral cortex. II. Continuation of the study of the ammonic system. J für Psychol Neurol. (1934) 46:113-77.

22. Hjorth-Simonsen A. Some intrinsic connections of the hippocampus in the rat: an experimental analysis. J Comp Neurol. (1973) 147:145-61. doi: 10.1002/cne.901470202

23. Andersen P, Bliss TV, Lomo T, Olsen LI, Skrede KK. Lamellar organization of hippocampal excitatory pathways. Acta physiologica Scandinavica. (1969) $76: 4 a-5 a$.

24. Duvernoy HM, Cattin F, Risold P-Y. The Human Hippocampus. New York, NY: Springer (2013)
25. Du F, Whetsell WOJr, Abou-Khalil B, Blumenkopf B, Lothman EW, Schwarcz R. Preferential neuronal loss in layer III of the entorhinal cortex in patients with temporal lobe epilepsy. Epilepsy Res. (1993) 16:223-33. doi: 10.1016/0920-1211(93) 90083-J

26. Hjorth-Simonsen A, Jeune B. Origin and termination of the hippocampal perforant path in the rat studied by silver impregnation. J Comp Neurol. (1972) 144:215-32. doi: 10.1002/cne.901440206

27. Amaral DG, Insausti R, Cowan WM. The entorhinal cortex of the monkey: I. Cytoarchitectonic organization. J Comp Neurol. (1987) 264:326-55. doi: $10.1002 / \mathrm{cne} .902640305$

28. Kohler C. Intrinsic projections of the retrohippocampal region in the rat brain. I. The subicular complex. J Comp Neurol. (1985) 236:504-22. doi: 10.1002/cne.902360407

29. Papez JW. A proposed mechanism of emotion. Arch Neurol Psychiatry (1937) 38:725-43. doi: 10.1001/archneurpsyc.1937.022602200 69003

30. Witter MP, Amaral DG. Entorhinal cortex of the monkey: V. Projections to the dentate gyrus, hippocampus, and subicular complex. J Comp Neurol. (1991) 307:437-59. doi: 10.1002/cne.903070308

31. Brodal P. The Central Nervous System - Structure and Function. New York, NY: Oxford University Press (2010).

32. Wightman G, Anderson VE, Martin J, Swash M, Anderton BH, Neary D, et al. Hippocampal and neocortical ubiquitin-immunoreactive inclusions in amyotrophic lateral sclerosis with dementia. Neurosci Lett. (1992) 139:26974. doi: 10.1016/0304-3940(92)90569-S

33. Okamoto K, Hirai S, Yamazaki T, Sun XY, Nakazato Y. New ubiquitinpositive intraneuronal inclusions in the extra-motor cortices in patients with amyotrophic lateral sclerosis. Neurosci Lett. (1991) 129:233-6. doi: 10.1016/0304-3940(91)90469-A

34. Okamoto K, Murakami N, Kusaka H, Yoshida M, Hashizume Y, Nakazato Y, et al. Ubiquitin-positive intraneuronal inclusions in the extramotor cortices of presenile dementia patients with motor neuron disease. J Neurol. (1992) 239:426-30. doi: 10.1007/BF00856806

35. Okamoto K, Hirai S, Amari M, Sakurai A. Electron micrograph of ubiquitin-positive intraneuronal inclusions in the extra-motor cortices in patients with amyotrophic lateral sclerosis. Neuropathology (1996) 16:112-6. doi: 10.1111/j.1440-1789.1996.tb00165.x

36. Nakano I. Temporal lobe lesions in amyotrophic lateral sclerosis with or without dementia: a neuropathological study. Neuropathology (1993) 13:215-27. doi: 10.1111/j.1440-1789.1993.tb00200.x

37. Takeda T, Uchihara T, Mochizuki Y, Mizutani T, Iwata M. Memory deficits in amyotrophic lateral sclerosis patients with dementia and degeneration of the perforant pathway A clinicopathological study. J Neurol Sci. (2007) 260:225-30. doi: 10.1016/j.jns.2007.05.010

38. Takeda T, Uchihara T, Arai N, Mizutani T, Iwata M. Progression of hippocampal degeneration in amyotrophic lateral sclerosis with or without memory impairment: distinction from Alzheimer disease. Acta Neuropathol. (2009) 117:35-44. doi: 10.1007/s00401-008-0447-2

39. Brettschneider J, Libon DJ, Toledo JB, Xie SX, McCluskey L, Elman L, et al. Microglial activation and TDP-43 pathology correlate with executive dysfunction in amyotrophic lateral sclerosis. Acta Neuropathol. (2012) 123:395-407. doi: 10.1007/s00401-011-0932-x

40. Bede P, Elamin M, Byrne S, McLaughlin RL, Kenna K, Vajda A, et al. Basal ganglia involvement in amyotrophic lateral sclerosis. Neurology (2013) 81:2107-15. doi: 10.1212/01.wnl.0000437313.80913.2c

41. Abdulla S, Machts J, Kaufmann J, Patrick K, Kollewe K, Dengler R, et al. Hippocampal degeneration in patients with amyotrophic lateral sclerosis. Neurobiol Aging (2014) 35:2639-45. doi: 10.1016/j.neurobiolaging.2014.05.035

42. Machts J, Loewe K, Kaufmann J, Jakubiczka S, Abdulla S, Petri S, et al. Basal ganglia pathology in ALS is associated with neuropsychological deficits. Neurology (2015) 85:1301-9. doi: 10.1212/WNL.00000000000 02017

43. Westeneng HJ, Verstraete E, Walhout R, Schmidt R, Hendrikse J, Veldink $\mathrm{JH}$, et al. Subcortical structures in amyotrophic lateral sclerosis. Neurobiol Aging (2015) 36:1075-82. doi: 10.1016/j.neurobiolaging.2014.09.002 
44. Sage CA, Peeters RR, Gorner A, Robberecht W, Sunaert S. Quantitative diffusion tensor imaging in amyotrophic lateral sclerosis. NeuroImage (2007) 34:486-99. doi: 10.1016/j.neuroimage.2006.09.025

45. Sage CA, Van Hecke W, Peeters R, Sijbers J, Robberecht W, Parizel $\mathrm{P}$, et al. Quantitative diffusion tensor imaging in amyotrophic lateral sclerosis: revisited. Hum Brain Mapp. (2009) 30:3657-75. doi: 10.1002/hbm. 20794

46. Barbagallo G, Nicoletti G, Cherubini A, Trotta M, Tallarico T, Chiriaco $\mathrm{C}$, et al. Diffusion tensor MRI changes in gray structures of the frontalsubcortical circuits in amyotrophic lateral sclerosis. Neurol Sci. (2014) 35:911-8. doi: 10.1007/s10072-013-1626-Z

47. Thivard L, Pradat P-F, Lehericy S, Lacomblez L, Dormont D, Chiras J, et al. Diffusion tensor imaging and voxel based morphometry study in amyotrophic lateral sclerosis: relationships with motor disability. $J$ Neurol Neurosurg Psychiatry (2007) 78:889-92. doi: 10.1136/jnnp.2006. 101758

48. Prell T, Peschel T, Hartung V, Kaufmann J, Klauschies R, Bodammer N, et al. Diffusion tensor imaging patterns differ in bulbar and limb onset amyotrophic lateral sclerosis. Clin Neurol Neurosurg. (2013) 115:1281-7. doi: 10.1016/j.clineuro.2012.11.031

49. Keil C, Prell T, Peschel T, Hartung V, Dengler R, Grosskreutz J. Longitudinal diffusion tensor imaging in amyotrophic lateral sclerosis. BMC Neurosci. (2012) 13:141. doi: 10.1186/1471-2202-13-141

50. Kassubek J, Muller HP, Del Tredici K, Brettschneider J, Pinkhardt EH, Lule D, et al. Diffusion tensor imaging analysis of sequential spreading of disease in amyotrophic lateral sclerosis confirms patterns of TDP-43 pathology. Brain (2014) 137(Pt 6):1733-40. doi: 10.1093/brain/awu090

51. Christidi F, Karavasilis E, Zalonis I, Ferentinos P, Giavri Z, Wilde EA, et al. Memory-related white matter tract integrity in amyotrophic lateral sclerosis: an advanced neuroimaging and neuropsychological study. Neurobiol Aging (2017) 49:69-78. doi: 10.1016/j.neurobiolaging.2016.09.014

52. Steinbach R, Loewe K, Kaufmann J, Machts J, Kollewe K, Petri S, et al. Structural hallmarks of amyotrophic lateral sclerosis progression revealed by probabilistic fiber tractography. J Neurol. (2015) 262:2257-70. doi: 10.1007/s00415-015-7841-1

53. Stoppel CM, Vielhaber S, Eckart C, Machts J, Kaufmann J, Heinze HJ, et al. Structural and functional hallmarks of amyotrophic lateral sclerosis progression in motor- and memory-related brain regions. Neuroimage Clin. (2014) 5:277-90. doi: 10.1016/j.nicl.2014.07.007

54. Agosta F, Valsasina P, Absinta M, Riva N, Sala S, Prelle A, et al. Sensorimotor functional connectivity changes in amyotrophic lateral sclerosis. Cereb Cortex (2011) 21:2291-8. doi: 10.1093/cercor/bhr002

55. Zhu W, Fu X, Cui F, Yang F, Ren Y, Zhang X, et al. ALFF value in right parahippocampal gyrus acts as a potential marker monitoring amyotrophic lateral sclerosis progression: a neuropsychological, voxel-based morphometry, and resting-state functional MRI study. J Mol Neurosci. (2015) 57:106-13. doi: 10.1007/s12031-015-0583-9

56. Heimrath J, Gorges M, Kassubek J, Muller HP, Birbaumer N, Ludolph $\mathrm{AC}$, et al. Additional resources and the default mode network: evidence of increased connectivity and decreased white matter integrity in amyotrophic lateral sclerosis. Amyotroph Lateral Scler Other Motor Neuron Disord. (2014) 15:537-45. doi: 10.3109/21678421.2014.911914

57. Loewe K, Machts J, Kaufmann J, Petri S, Heinze HJ, Borgelt C, et al. Widespread temporo-occipital lobe dysfunction in amyotrophic lateral sclerosis. Sci Rep. (2017) 7:40252. doi: 10.1038/srep40252

58. Abrahams S, Goldstein LH, Al-Chalabi A, Pickering A, Morris RG, Passingham RE, et al. Relation between cognitive dysfunction and pseudobulbar palsy in amyotrophic lateral sclerosis. J Neurol Neurosurg Psychiatry (1997) 62:464-72. doi: 10.1136/jnnp.62.5.464

59. Chari G, Shaw PJ, Sahgal A. Nonverbal visual attention, but not recognition memory of learning, processes are impaired in motor neurone disease. Neuropsychologia (1996) 34:377-85. doi: 10.1016/0028-3932(95)00122-0

60. Frank B, Haas J, Heinze HJ, Stark E, Munte TF. Relation of neuropsychological and magnetic resonance findings in amyotrophic lateral sclerosis: evidence for subgroups. Clin Neurol Neurosurg. (1997) 99:79-86. doi: 10.1016/S0303-8467(97)80001-7

61. Hanagasi HA, Gurvit IH, Ermutlu N, Kaptanoglu G, Karamursel S, Idrisoglu HA, et al. Cognitive impairment in amyotrophic lateral sclerosis: evidence from neuropsychological investigation and event-related potentials. Brain Res Cogn Brain Res. (2002) 14:234-44. doi: 10.1016/S0926-6410(02) 00110-6

62. Iwasaki $\mathrm{Y}$, Kinoshita $\mathrm{M}$, Ikeda $\mathrm{K}$, Takamiya $\mathrm{K}$, Shiojima $\mathrm{T}$. Cognitive impairment in amyotrophic lateral sclerosis and its relation to motor disabilities. Acta Neurol Scand. (1990) 81:141-3. doi: 10.1111/j.1600-0404.1990.tb00950.x

63. Ludolph AC, Langen KJ, Regard M, Herzog H, Kemper B, Kuwert T, et al. Frontal lobe function in amyotrophic lateral sclerosis: a neuropsychologic and positron emission tomography study. Acta Neurol Scand. (1992) 85:819. doi: 10.1111/j.1600-0404.1992.tb04003.x

64. Massman PJ, Sims J, Cooke N, Haverkamp LJ, Appel V, Appel SH. Prevalence and correlates of neuropsychological deficits in amyotrophic lateral sclerosis. J Neurol Neurosurg Psychiatry (1996) 61:450-5. doi: 10.1136/jnnp. 61.5.450

65. Mantovan MC, Baggio L, Dalla Barba G, Smith P, Pegoraro E, Soraru G, et al. Memory deficits and retrieval processes in ALS. Eur J Neurol. (2003) 10:221-7. doi: 10.1046/j.1468-1331.2003.00607.x

66. Christidi F, Zalonis I, Smyrnis N, Evdokimidis I. Selective attention and the three-process memory model for the interpretation of verbal free recall in amyotrophic lateral sclerosis. J Int Neuropsychol Soc. (2012) 18:809-18. doi: $10.1017 /$ S1355617712000562

67. Machts J, Bittner V, Kasper E, Schuster C, Prudlo J, Abdulla S, et al. Memory deficits in amyotrophic lateral sclerosis are not exclusively caused by executive dysfunction: a comparative neuropsychological study of amnestic mild cognitive impairment. BMC Neurosci. (2014) 15:83. doi: 10.1186/1471-2202-15-83

68. Burke T, Lonergan K, Pinto-Grau M, Elamin M, Bede P, Madden C, et al. Visual encoding, consolidation, and retrieval in amyotrophic lateral sclerosis: executive function as a mediator, and predictor of performance. Amyotroph Lateral Scler Other Motor Neuron Disord. (2017) 18:193-201. doi: 10.1080/21678421.2016.1272615

69. Nakano I, Iwatsubo T, Hashizume Y, Mizutani T, Mannen T. Amyotrophic lateral sclerosis: lesions in the apical cortex and some deeper structures of the temporal lobes. Neuropathology (1992) 12:69-77.

70. Goedert M, Spillantini MG. A century of Alzheimer's disease. Science (2006) 314:777-81. doi: 10.1126/science.1132814

71. Janssens J, Van Broeckhoven C. Pathological mechanisms underlying TDP43 driven neurodegeneration in FTLD-ALS spectrum disorders. Hum Mol Genet. (2013) 22:R77-87. doi: 10.1093/hmg/ddt349

72. Steward O. Topographic organization of the projections from the entorhinal area to the hippocampal formation of the rat. JComp Neurol. (1976) 167:285314. doi: 10.1002/cne.901670303

73. Ishizuka N, Weber J, Amaral DG. Organization of intrahippocampal projections originating from CA3 pyramidal cells in the rat. J Comp Neurol. (1990) 295:580-623. doi: 10.1002/cne.9029 50407

74. Geser F, Brandmeir NJ, Kwong LK, Martinez-Lage M, Elman L, McCluskey $\mathrm{L}$, et al. Evidence of multisystem disorder in whole-brain map of pathological TDP-43 in amyotrophic lateral sclerosis. Arch neurology. (2008) 65:636-41. doi: 10.1001/archneur.65.5.636

75. Geser F, Prvulovic D, O’Dwyer L, Hardiman O, Bede P, Bokde AL, et al. On the development of markers for pathological TDP-43 in amyotrophic lateral sclerosis with and without dementia. Prog Neurobiol. (2011) 95:649-62. doi: 10.1016/j.pneurobio.2011.08.011

76. Schmidt R, de Reus MA, Scholtens LH, van den Berg LH, van den Heuvel MP. Simulating disease propagation across white matter connectome reveals anatomical substrate for neuropathology staging in amyotrophic lateral sclerosis. NeuroImage (2016) $124(\mathrm{Pt}$ A):762-9. doi: 10.1016/j.neuroimage.2015.04.005

77. Braak H, Brettschneider J, Ludolph AC, Lee VM, Trojanowski JQ, Del Tredici K. Amyotrophic lateral sclerosis-a model of corticofugal axonal spread. Nat Rev Neurol. (2013) 9:708-14. doi: 10.1038/nrneurol.20 13.221

78. Bede P, Omer T, Finegan E, Chipika RH, Iyer PM, Doherty MA, et al. Connectivity-based characterisation of subcortical grey matter pathology in frontotemporal dementia and ALS: a multimodal neuroimaging study. Brain Imag Behav. (2018) doi: 10.1007/s11682-018-9837-9. [Epub ahead of print]. 
79. Bak TH, Chandran S. What wires together dies together: verbs, actions and neurodegeneration in motor neuron disease. Cortex (2012) 48:936-44. doi: 10.1016/j.cortex.2011.07.008

80. Bede P, Hardiman O. Lessons of ALS imaging: Pitfalls and future directions - a critical review. Neuroimage Clin. (2014) 4:436-43. doi: 10.1016/j.nicl.2014.02.011

81. Turner MR, Agosta F, Bede P, Govind V, Lulé D, Verstraete E. Neuroimaging in amyotrophic lateral sclerosis. Biomarkers Med. (2012) 6:319-37. doi: 10.2217/bmm.12.26

82. Anderson VE, Cairns NJ, Leigh PN. Involvement of the amygdala, dentate and hippocampus in motor neuron disease. J Neurol Sci. (1995) 129(Suppl):75-8. doi: 10.1016/0022-510X(95)00069-E

83. Grosskreutz J, Kaufmann J, Fradrich J, Dengler R, Heinze HJ, Peschel T. Widespread sensorimotor and frontal cortical atrophy in Amyotrophic Lateral Sclerosis. BMC Neurol. (2006) 6:17. doi: 10.1186/1471-23 77-6-17

84. Kato Y, Matsumura K, Kinosada Y, Narita Y, Kuzuhara S, Nakagawa T. Detection of pyramidal tract lesions in amyotrophic lateral sclerosis with magnetization-transfer measurements. Am J Neuroradiol. (1997) 18: $1541-7$.

85. Neumann M, Sampathu DM, Kwong LK, Truax AC, Micsenyi MC, Chou TT, et al. Ubiquitinated TDP-43 in frontotemporal lobar degeneration and amyotrophic lateral sclerosis. Science (2006) 314:130-3. doi: 10.1126/science.1134108

86. den Heijer T, der Lijn F, Vernooij MW, de Groot M, Koudstaal PJ, van der Lugt A, et al. Structural and diffusion MRI measures of the hippocampus and memory performance. NeuroImage (2012) 63:1782-9. doi: 10.1016/j.neuroimage.2012.08.067

87. Christidi F, Zalonis I, Kyriazi S, Rentzos M, Karavasilis E, Wilde $\mathrm{EA}$, et al. Uncinate fasciculus microstructure and verbal episodic memory in amyotrophic lateral sclerosis: a diffusion tensor imaging and neuropsychological study. Brain Imag Behav. (2014) 8:497-505. doi: 10.1007/s11682-013-9271-y

88. Sarro L, Agosta F, Canu E, Riva N, Prelle A, Copetti M, et al. Cognitive functions and white matter tract damage in amyotrophic lateral sclerosis: a diffusion tensor tractography study. Am J Neuroradiol. (2011) 32:1866-72. doi: 10.3174/ajnr.A2658

89. Sato K, Aoki S, Iwata NK, Masutani Y, Watadani T, Nakata Y, et al. Diffusion tensor tract-specific analysis of the uncinate fasciculus in patients with amyotrophic lateral sclerosis. Neuroradiology (2010) 52:72933. doi: 10.1007/s00234-010-0653-1

90. Augustinack JC, Helmer K, Huber KE, Kakunoori S, Zollei L, Fischl B. Direct visualization of the perforant pathway in the human brain with ex vivo diffusion tensor imaging. Front Hum Neurosci. (2010) 4:42. doi: 10.3389/fnhum.2010.00042

91. Christidi F, Bigler ED, McCauley SR, Schnelle KP, Merkley TL, Mors $\mathrm{MB}$, et al. Diffusion tensor imaging of the perforant pathway zone and its relation to memory function in patients with severe traumatic brain injury. J Neurotrauma (2011) 28:711-25. doi: 10.1089/neu.201 0.1644

92. Kalus P, Slotboom J, Gallinat J, Mahlberg R, Cattapan-Ludewig K, Wiest $\mathrm{R}$, et al. Examining the gateway to the limbic system with diffusion tensor imaging: the perforant pathway in dementia. Neuroimage (2006) 30:713-20. doi: 10.1016/j.neuroimage.2005.10.035

93. Rogalski EJ, Murphy CM, deToledo-Morrell L, Shah RC, Moseley ME, Bammer R, et al. Changes in parahippocampal white matter integrity in amnestic mild cognitive impairment: a diffusion tensor imaging study. Behav Neurol. (2009) 21:51-61. doi: 10.1155/2009/408037

94. Yassa MA, Muftuler LT, Stark CE. Ultrahigh-resolution microstructural diffusion tensor imaging reveals perforant path degradation in aged humans in vivo. Proc Natl Acad Sci USA. (2010) 107:12687-91. doi: 10.1073/pnas.1002113107

95. Menke RA, Proudfoot M, Wuu J, Andersen PM, Talbot K, Benatar $\mathrm{M}$, et al. Increased functional connectivity common to symptomatic amyotrophic lateral sclerosis and those at genetic risk. J Neurol Neurosurg Psychiatry (2016) 87:580-8. doi: 10.1136/jnnp-2015-3 11945
96. Ringholz GM, Appel SH, Bradshaw M, Cooke NA, Mosnik DM, Schulz PE. Prevalence and patterns of cognitive impairment in sporadic ALS. Neurology (2005) 65:586-90. doi: 10.1212/01.wnl.0000172911.39167.b6

97. Abe K, Fujimura H, Toyooka K, Sakoda S, Yorifuji S, Yanagihara T. Cognitive function in amyotrophic lateral sclerosis. J Neurol Sci. (1997) 148:95-100. doi: 10.1016/S0022-510X(96)05338-5

98. Abrahams S, Leigh PN, Harvey A, Vythelingum GN, Grise D, Goldstein LH. Verbal fluency and executive dysfunction in amyotrophic lateral sclerosis (ALS). Neuropsychologia (2000) 38:734-47. doi: 10.1016/S0028-3932(99)00146-3

99. Kew JJ, Goldstein LH, Leigh PN, Abrahams S, Cosgrave N, Passingham $\mathrm{RE}$, et al. The relationship between abnormalities of cognitive function and cerebral activation in amyotrophic lateral sclerosis. A neuropsychological and positron emission tomography study. Brain (1993) 116 (Pt 6):1399-423. doi: 10.1093/brain/116.6.1399

100. Gallassi R, Montagna P, Ciardulli C, Lorusso S, Mussuto V, Stracciari A. Cognitive impairment in motor neuron disease. Acta Neurol Scand. (1985) 71:480-4. doi: 10.1111/j.1600-0404.1985.tb03231.x

101. Strong MJ, Grace GM, Orange JB, Leeper HA, Menon RS, Aere C. A prospective study of cognitive impairment in ALS. Neurology (1999) 53:1665-70. doi: 10.1212/WNL.53.8.1665

102. Raaphorst J, van Tol MJ, de Visser M, van der Kooi AJ, Majoie CB, van den Berg LH, et al. Prose memory impairment in amyotrophic lateral sclerosis patients is related to hippocampus volume. Eur J Neurol. (2015) 22:547-54. doi: 10.1111/ene.12615

103. Verstraete E, Turner MR, Grosskreutz J, Filippi M, Benatar M. Mind the gap: the mismatch between clinical and imaging metrics in ALS. Amyotroph Lateral Scler Other Motor Neuron Disord. (2015) 16:524-9. doi: 10.3109/21678421.2015.1051989

104. Cattie JE, Woods SP, Arce M, Weber E, Delis DC, Grant I. Construct validity of the item-specific deficit approach to the California verbal learning test (2nd Ed) in HIV infection. Clin Neuropsychol. (2012) 26:288-304. doi: 10.1080/13854046.2011.653404

105. Wright MJ, Woo E, Schmitter-Edgecombe M, Hinkin CH, Miller EN, Gooding AL. The item-specific deficit approach to evaluating verbal memory dysfunction: rationale, psychometrics, and application. J Clin Exp Neuropsychol. (2009) 31:790-802. doi: 10.1080/13803390802508918

106. Wright MJ, Schmitter-Edgecombe M, Woo E. Verbal memory impairment in severe closed head injury: the role of encoding and consolidation. J Clin Exp Neuropsychol. (2010) 32:728-36. doi: 10.1080/138033909035 12652

107. Bede P, Querin G, Pradat PF. The changing landscape of motor neuron disease imaging: the transition from descriptive studies to precision clinical tools. Curr Opin Neurol. (2018). doi: 10.1097/WCO.0000000000000569. [Epub ahead of print].

108. Kaufmann P, Levy G, Montes J, Buchsbaum R, Barsdorf AI, Battista V, et al. Excellent inter-rater, intra-rater, and telephone-administered reliability of the ALSFRS-R in a multicenter clinical trial. Amyotroph Lateral Scler. (2007) 8:42-6. doi: 10.1080/17482960600888156

109. Gooch CL, Pullman SL, Shungu DC, Ulug AM, Chane S, Gordon PH, et al. Motor unit number estimation (MUNE) in diseases of the motor neuron: utility and comparative analysis in a multimodal biomarker study. Suppl Clin Neurophysiol. (2009) 60:153-62. doi: 10.1016/S1567-424X(08)0 0015-9

110. Blasco H, Patin F, Descat A, Garcon G, Corcia P, Gele P, et al. A pharmaco-metabolomics approach in a clinical trial of ALS: identification of predictive markers of progression. PLoS ONE (2018) 13:e0198116. doi: 10.1371/journal.pone.0198116

111. Elamin M, Bede P, Byrne S, Jordan N, Gallagher L, Wynne B, et al. Cognitive changes predict functional decline in ALS A population-based longitudinal study. Neurology (2013) 80:1590-7. doi: 10.1212/WNL.0b013e31828 f18ac

112. Byrne S, Elamin M, Bede P, Shatunov A, Walsh C, Corr B, et al. Cognitive and clinical characteristics of patients with amyotrophic lateral sclerosis carrying a C9orf72 repeat expansion: a population-based cohort study. Lancet Neurol. (2012) 11:232-40. doi: 10.1016/S1474-4422(12)7 0014-5 
113. Bede P, Bokde ALW, Byrne S, Elamin M, McLaughlin RL, Kenna K, et al. Multiparametric MRI study of ALS stratified for the C9orf72 genotype. Neurology (2013) 81:361-9. doi: 10.1212/WNL.0b013e31829c5eee

114. Omer T, Finegan E, Hutchinson S, Doherty M, Vajda A, McLaughlin RL, et al. Neuroimaging patterns along the ALS-FTD spectrum: a multiparametric imaging study. Amyotroph Lateral Scler Other Motor Neuron Disord. (2017) 18:611-23. doi: 10.1080/21678421.2017.1332077

115. Walhout R, Schmidt R, Westeneng HJ, Verstraete E, Seelen M, van Rheenen W, et al. Brain morphologic changes in asymptomatic C9orf72 repeat expansion carriers. Neurology (2015) 85:1780-8. doi: 10.1212/WNL.0000000000002135
Conflict of Interest Statement: The authors declare that the research was conducted in the absence of any commercial or financial relationships that could be construed as a potential conflict of interest.

Copyright (c) 2018 Christidi, Karavasilis, Velonakis, Ferentinos, Rentzos, Kelekis, Evdokimidis and Bede. This is an open-access article distributed under the terms of the Creative Commons Attribution License (CC BY). The use, distribution or reproduction in other forums is permitted, provided the original author(s) and the copyright owner(s) are credited and that the original publication in this journal is cited, in accordance with accepted academic practice. No use, distribution or reproduction is permitted which does not comply with these terms. 